\title{
3-D Atlas of Stars and Galaxies
}

Springer-Verlag London Ltd. 
Richard Monkhouse and John Cox

\section{3-D ATLAS \\ OF STARS \\ AND GALAXIES}


Richard Monkhouse, MA

John Cox, MA

Frontispiece - The Hipparcos Satellite Observatory: the 'Star Machine' (Photo ESA)

\section{ISBN 978-1-4471-1039-2}

British Library Cataloguing in Publication Data

Monkhouse, Richard, 1950-

3-D atlas of stars and galaxies

1.Stars - Atlases

I.Title II. Cox, John, 1947-

$523.8^{\prime} 0223$

ISBN 978-1-4471-1039-2

Library of Congress Cataloging-in-Publication Data

Monkhouse, Richard.

3-D atlas of stars and galaxies/Richard Monkhouse and John Cox.

p. $\mathrm{cm}$.

Includes bibliographical references.

ISBN 978-1-4471-1039-2 ISBN 978-0-85729-325-1 (eBook)

DOI 10.1007/978-0-85729-325-1

1. Stars-Atlases. 2. Galaxies-Atlases. I. Cox, John, 1947- II. Title.

III. Title: Three-D atlas of stars and galaxies.

QB65.M586 1999

523.8'0222'3-dc21 99-26690

Apart from any fair dealing for the purposes of research or private study, or criticism or review, as permitted under the Copyright, Designs and Patents Act 1988, this publication may only be reproduced, stored or transmitted, in any form or by any means, with the prior permission in writing of the publishers, or in the case of reprographic reproduction in accordance with the terms of licences issued by the Copyright Licensing Agency. Enquiries concerning reproduction outside those terms should be sent to the publishers.

c) Springer-Verlag London 2000

Originally published by Springer-Verlag London Limited in 2000

Softcover reprint of the hardcover 1st edition 2000

The use of registered names, trademarks etc. in this publication does not imply, even in the absence of a specific statement, that such names are exempt from the relevant laws and regulations and therefore free for general use.

The publisher makes no representation, express or implied, with regard to the accuracy of the information contained in this book and cannot accept any legal responsibility or liability for any errors or omissions that may be made.

Typesetting: The Midlands Book Typesetting Company, Loughborough, UK 
Introduction ...................................................................................... $\quad 6$

The Near Star Maps .............................................................................. $\quad 8$

The Bright Star Maps ................................................................................. 26

The Galaxy Maps ...................................................................................... 64

Special Views ....................................................................................... 90

Sources and Acknowledgements ........................................................... 95 